\title{
Reduction of cutaneous von Frey thresholds in boys with autism following a year of tactile and emotional stimulation
}

\author{
Adhara I. Fernández-Lechuga', Linda Y. Nuñez-Arcos ${ }^{1}$, Porfirio Carrillo², Luis I. García', \\ Genaro A. Coria-Ávila1', Rebeca Toledo ${ }^{1}$, María Elena Hernández ${ }^{1}$, and Jorge Manzo ${ }^{1 *}$ \\ ${ }^{1}$ Centro de Investigaciones Cerebrales, ${ }^{2}$ Instituto de Neuroetología. Universidad Veracruzana, Xalapa, Veracruz, Mexico
}

\begin{abstract}
Background: Autism spectrum disorder is an alteration of neurodevelopment with a conspicuous display of behaviors in children between 2 and 3 years of age. Basic behavioral manifestations are social isolation, language impairment, and motor problems. However, there are also manifestations related to sensory perception, although knowledge about tactile stimulation is yet poorly understood. Objective: We aimed to determine changes in the cutaneous sensitivity of autistic boys following a program of tactile and emotional stimulation. Methods: Sensory stimulation was applied as therapy to six autistic boys 5-12 years old. As stimuli, we used bubble paper and a skin massager twice a week for 1 year. During stimulation, kids were allowed to walk in socks during 2 min on a $2 \times 2 \mathrm{~m}$ carpet made of bubble paper and asked to burst the bubbles. In addition, a handheld massager was used to stimulate the skin on the forearm and face cheek with level 2 of intensity for 2 min. Following stimulation, the cutaneous sensitivity threshold was obtained using von Frey fibers on the forearm and face cheek. Kids were asked to keep their eyes closed and to indicate their perception by pointing with a finger toward the stimulated area. Results: Our data indicate that kids were capable of perceiving smaller fibers with consecutive therapy sessions. Conclusion: Tactile and sensory stimulation to autistic children modifies cutaneous sensitivity, perhaps with an improved perception of the general environment and consequently social behavior.
\end{abstract}

Key words: Skin sensitivity. Emotional response. Enriched stimulation. Autistic boys.

\section{Reducción en el umbral cutáneo a von Fray en niños con autismo después de un año de estimulación tactil y emocional}

\section{Resumen}

Antecedentes: El trastorno del espectro autista es una alteración del neurodesarrollo con manifestaciones conductuales particulares en niños entre los 2-3 años de edad. Las conductas básicas son el aislamiento social, alteraciones del lenguaje y problemas motores. Sin embargo, existen también modificaciones relacionadas con la percepción sensorial, aunque el conocimiento sobre ello es aún pobre. Objetivo: Tuvimos el propósito de determinar la sensibilidad cutánea de niños con autismo siguiendo un programa de estimulación táctil y emocional. Métodos: Aplicamos dos estímulos sensoriales a 6 niños con autismo de 5 a 12 años de edad. Los estímulos utilizados fueron papel burbuja y un masajeador, dos veces por semana durante un año. Un cuadro de $2 \times 2 \mathrm{~m}$ de papel burbuja se colocó en el piso y la prueba consistió en que cada niño

Correspondence:

*Jorge Manzo

E-mail: jmanzo@uv.mx

DOI: 10.24875/RMN.20000002
Available online: 25-05-2021

Rev Mex Neuroci. 2021;22(3):85-88

www.revmexneurociencia.com

2604-6180/ (c) 2020 Academia Mexicana de Neurología A.C. Published by Permanyer. This is an open access article under the CC BY-NC-ND license (http://creativecommons.org/licenses/by-nc-nd/4.0/). 
caminara en calcetas por dos minutos tratando de reventar las burbujas. Un masajeador manual fue utilizado para estimular la piel del antebrazo y la mejilla a un nivel 2 de intensidad por dos minutos. Después de los estímulos, el umbral a la sensibilidad cutánea se obtuvo usando fibras de von Fray sobre el antebrazo y la mejilla, pidiendo a los niños mantener los ojos cerrados y señalando la percepción con un dedo el área estimulada. Resultados: A medida que la terapia se aplicó continuamente, cada niño fue capaz de percibir fibras más pequeñas. Conclusiones: Una estimulación enriquecida táctil y sensorial de niños con autismo modifica la sensibilidad cutánea, probablemente con una percepción mejorada del ambiente en general y consecuentemente de la conducta social.

Palabra clave: Sensibilidad cutánea. Respuesta emocional. Estimulación enriquecida. Niños con autismo.

\section{Introduction}

Autism spectrum disorder (ASD) is a range of modified behavioral displays that become conspicuous in children about 2-3 years old. The most remarkable behaviors include decreased social interaction, language impairments, and repetitive or stereotyped movements. However, there is also the prevailing attribute allied to the physiology of sensory processing. Since the seminal work of Kanner ${ }^{1}$, it was stated that in autism loud noises trigger panic or emotional crisis, and to date, it is known that these responses are related to a multisensory dysfunction of the auditory, visual, oral, and cutaneous pathways ${ }^{2}$. Touch is a powerful stimulation to the skin with the potency to rewire neural circuits that are reflected as modifications in social behavior during development and adulthood $^{3}$. In animal studies, we have shown that toxic effect to cutaneous $C$ and $A \delta$ afferent fibers during development results in increased motor patterns as grooming or scratching ${ }^{4}$ indicating repetitive movements and suggesting that these cutaneous afferent fibers could be compromised in the stereotyped movements, as those seen in autism. On the other hand, some authors reported that foot massage triggers neuroendocrine responses that could be therapeutic for autism ${ }^{5}$. Thus, the literature is now becoming plenty of data on sensory processing, suggesting that cutaneous sensitivity may be another central core symptom in autism ${ }^{6}$. Hence, we argue that it is important for the quality of life in autism to develop some strategies to modify the skin sensitivity. Considering this, we investigated whether the tactile threshold of autistic boys could be modified as a consequence of long-term therapy of skin and sensory stimulation.

\section{Methods}

This was a longitudinal study in which all participants were tested continuously for 1 year. The protocol was approved by the Ethics Committee of the Brain Research Center at our university, and procedures were based on the Helsinki Declaration. Parents of the participants received a thorough explanation of the procedures and, on acceptance, signed an informed consent to allow their boys to be included in the study.

\section{Participants}

Six boys with autism from 5 to 12 years of age were included in the study; all of them in the Severity Level 1 according to DSM- $5^{6}$. Kids received stimulation with bubble paper and a massager, twice a week for 1 year. In each test, the bubble paper was used for feet sensory stimulation. A carpet of $2 \times 2 \mathrm{~m}$ of bubble paper was placed on the floor and kids were asked to walk on in socks for 2 min trying to burst the bubbles. Bursting of bubbles produced both feet tactile stimulation and auditory stimulation along with apparent emotional responses. Immediately after the bubble paper activity, boys were asked to sit on a chair and a handheld massager (Homedics, Mexico) was used to stimulate the forearm and the face cheek with a level 2 of intensity for 2 min each area and in random left or right side. Following the massage, boys were asked to close their eyes and the forearm and cheek were stimulated with von Frey fibers of different size to determine the cutaneous sensitivity threshold. Boys were asked to indicate perception of the fiber by pointing the stimulated area with a finger. A cohort group of 10 boys with typical development was included in the study as controls and was analyzed under the same procedures.

The number of sessions required to (1) remove the shoes, (2) accept the massage, or (3) close the eyes on request, was analyzed with the Long-rank Mantel-Cox test, and is represented in a survival curve (Fig. 1). Cutaneous sensitivity (threshold) was assessed every month by detecting the smallest von Frey fiber that evoked a skin sensation. The size of von Frey fibers and the session were analyzed with a Pearson $r$ correlation and represented in a graph with the median and interquartile range (Fig. 2). The fact that typical developed boys responded right from the first test and perceived the smallest fiber, precluded their inclusion in the statistics. Analysis was 


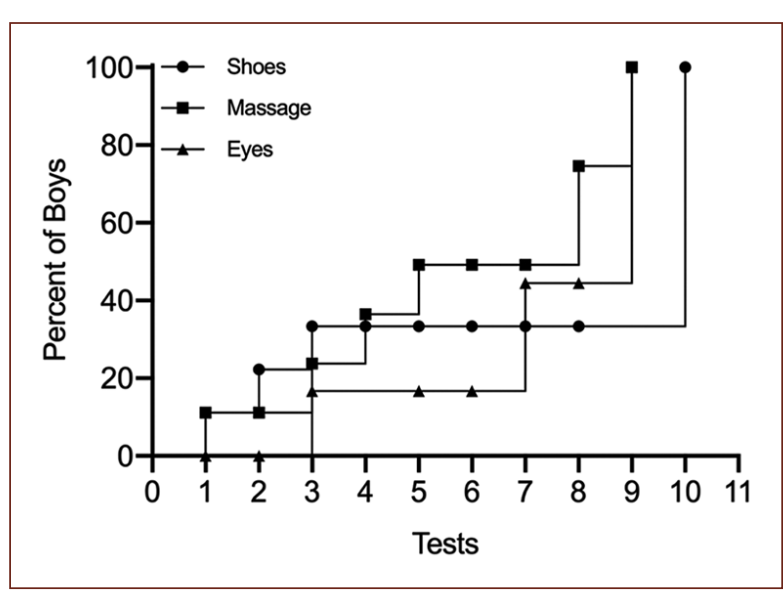

Figure 1. Number of sessions required for $100 \%$ of the boys to accept remove their shoes, walk on bubble paper, accept the massager, and close their eyes for perceiving the von Fray fibers. The survival steps were similar for the three parameters and no significant differences were detected.

developed with Prism 8 (GraphPad Software, USA), and significant differences were indicated when $p<0.05$.

\section{Results}

The first challenge was related to the lack of propensity of the boys to remove their shoes on request and walk on the bubble paper, to accept the massager, or to close their eyes for skin detection of the von Fray fibers. However, boys responded positively after a continuous period of being asked for the procedures. Fig. 1 shows that 10 tests were required for all boys to get the disposition for the three challenges, all of them in a similar acceptance curve, with no significant differences among them.

The different sensitivity tests in each month were compiled into a single value for analysis to get 12 values for the year. The smallest von Frey fiber in our set has a value of 1.6 and the largest of 6.65 , with a total of 20 fibers of different size. Data showed that boys with typical development perceived the smallest fiber in the first test, whereas autistic boys perceived fibers with the average size of 4.0. Longitudinal curves showed that autistic boys modified their threshold perception during consecutive tests. At the end of the year, their perception was similar to those of typically developed boys in both the forearm and cheek (Fig. 2).

\section{Discussion}

The incorporation of autistic boys into new tasks is a challenge due to their strong predisposition to routines.

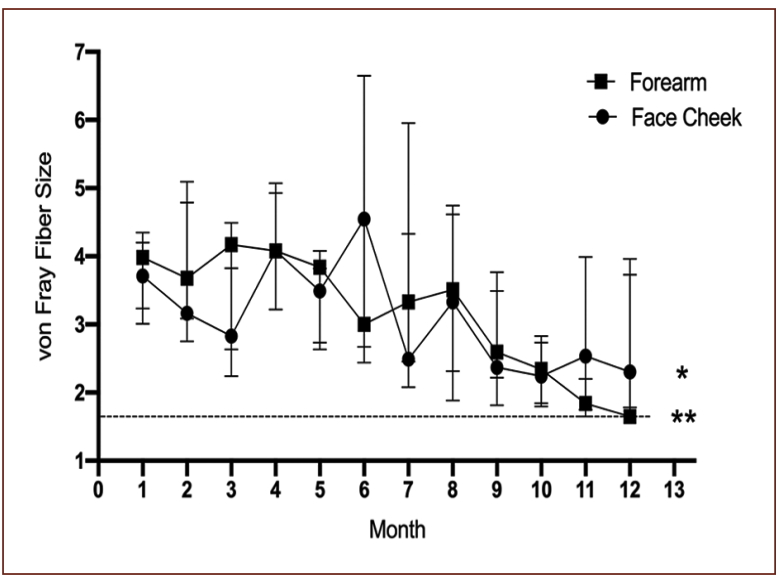

Figure 2. Tactile sensitivity according to the used von Fray fiber size. Graph shows that tactile sensitivity was constantly increasing in boys with autism from the $1^{\text {st }}$ to the $12^{\text {th }}$ month, considering that a smallest fiber was detected at the long run. The same curve shape was observed for both the arm and face. Control kids (typical development) perceived the smallest fiber right from the first month (dash line). Each point represents the median and interquartile range. The Pearson $r$ correlation showed that each curve had a significant slope from month 1 to month $12\left({ }^{*} p<0.05 ;{ }^{* *} p<0.01\right)$.

However, we have previously shown that motor and cognitive improvements are possible following long-term stimulation with virtual sports ${ }^{7}$. Now, to accomplish the purpose of the present study, it was a requirement that all kids were able to remove their shoes, walk and press bubble paper, sit and keep their eyes closed, and point the place where they detected the von Frey fiber. Although they eventually did it successfully, it was not immediate and took them about 5 weeks to agree follow instructions. Thus, responding to procedural instructions is not an unattainable challenge for autistic boys, although they take time to master the task. By contrast, boys with typical development followed instructions right from the $1^{\text {st }}$ day. Thus, one speculation is that the kind of repeated stimulation provided to autistic kids in the present study improves the function of brain regions involved in attention, decision-making, habits, and procedural memory, such as the prefrontal cortex, basal ganglia, and cerebellum, among others ${ }^{8-10}$.

On the other hand, it is known that skin sensitivity is a remarkable function that allows a wide perception of the environment and stimulates the development of appropriate neural circuits in the central nervous system. Our data showed that at the beginning, the autistic boys had a higher threshold to perceive von Frey fibers. Interestingly, due to the constant engagement in both sensory and the bubble-induced emotional stimulation, 
their threshold was reduced to typical levels in both the forearm and cheek. Thus, once again, a speculation is that stimulation as provided here successfully modified the function of some parameters of the somatosensory neural circuits. Starting at the skin level, it is known that typical and autistic kids have a similar histology and are similarly prone to pediatric injuries ${ }^{11}$. In addition, the skin conductance appears to be equivalent in autistic and typical children, which allows the use of this parameter to measure social anxiety and the impact of animals to induce anxiolytic effects in autistic kids ${ }^{12}$. Furthermore, skin massage seems to be relevant to manage sleep problems in autism ${ }^{13}$, suggesting that skin-induced changes might occur at central levels.

Indeed, the somatosensory cortex functional connectivity is abnormal in autism ${ }^{14}$. Thus, we hypothesize that at the beginning of this study, the autistic kids responded to altered skin-to-cortex functional connection, which was probably rewired following a prolonged period of stimulation. Hence, our guess is that those circuits became activated in their potency for neural plasticity, considering that this feature is triggered by sensory experiences ${ }^{15}$. Further research is needed to explain how such plasticity response could be correlated to the observed behavior. We argue that skin stimulation is a channel for information that is relevant for social behavior $^{16}$. In fact, social neuroscience, that is, the study of the neural basis of social behavior, has already proposed several brain structures underlying social interactions $^{17}$. Some of them, as the insular cortex, is modified significantly by tactile afferents from the skin in response to pleasant and social relevant stimuli ${ }^{18,19}$. Thus, we suggest that the kind of continuous stimulation used in this study was strong enough to modify the circuits and improve the tactile sensation in these boys with autism. Those changes might be relevant to improve perception of the general environment and consequently improve social behavior, but this statement still deserves further studies.

\section{Conclusion}

Long-term therapy with tactile and sensory stimulation in autistic boys modified their cutaneous sensitivity, resulting in thresholds similar to those observed in boys with typical development.

\section{Funding}

None.

\section{Conflicts of interest}

None.

\section{Ethical disclosures}

Protection of human and animal subjects. The authors declare that the procedures followed were in accordance with the regulations of the relevant clinical research ethics committee and with those of the Code of Ethics of the World Medical Association (Declaration of Helsinki).

Confidentiality of data. The authors declare that no patient data appear in this article.

Right to privacy and informed consent. The authors declare that no patient data appear in this article.

\section{References}

1. Kanner L. Autistic disturbances of affective contact. Nerv Child. 1943:2:217-50.

2. Kern JK, Trivedi MH, Grannemann BD, Garver CR, Johnson DG, Andrews AA, et al. Sensory correlations in autism. Autism. 2007;11:123-34.

3. Björnsdotter M, Gordon I, Pelphrey KA, Olausson H, Kaiser MD. Development of brain mechanisms for processing affective touch. Front Behav Neurosci. 2014;8:24.

4. Carrillo P, Manzo J, Martinez-Gomez M, Salas M, Pacheco P. Neonatal capsaicin administration: effects on behavioral development of the rat. Pharmacol Biochem Behav. 1994;48:447-52.

5. Li Q, Becker B, Wernicke J, Chen Y, Zhang Y, Li R, et al. Foot massage evokes oxytocin release and activation of orbitofrontal cortex and superior temporal sulcus. Psychoneuroendocrinology. 2018;101:193-203.

6. American Psychiatric Association. Diagnostic and Statistical Manual of Mental Disorders (DSM- $\left.5^{\circledR}\right)$. Arlington, VA: American Psychiatric Association; 2013.

7. Crespo CN, Garcia LI, Coria GA, Carrillo P, Hernandez ME, Manzo J. Mejora de las habilidades motoras y cognitivas de niños con autismo después de un periodo prolongado de juego con deportes virtuales. eNeurobiol. 2016;7:070716.

8. Robertson EM, Tormos JM, Maeda F, Pascual-Leone A. The role of the dorsolateral prefrontal cortex during sequence learning is specific for spatial information. Cereb Cortex. 2001;11:628-35.

9. Ullman MT. Contributions of memory circuits to language: the declarative/ procedural model. Cognition. 2004:92:231-70.

10. Lum J, Conti-Ramsden G, Page D, Ullman MT. Working, declarative and procedural memory in specific language impairment. Cortex. 2012;48:1138-54.

11. Slingsby $B$, Yatchmink $Y$, Goldberg A. Typical skin injuries in children with autism spectrum disorder. Clin Pediatr (Phila). 2017:56:942-6.

12. O'Haire ME, McKenzie SJ, Beck AM, Slaughter V. Animals may act as social buffers: skin conductance arousal in children with autism spectrum disorder in a social context. Dev Psychobiol. 2015:57:584-95.

13. McLay LL, France K. Empirical research evaluating non-traditional approaches to managing sleep problems in children with autism. Dev Neurorehab. 2014;19:1-12.

14. Khan S, Michmizos K, Tommerdahl M, Ganesan S, Kitzbichler MG, Zetino $M$, et al. Somatosensory cortex functional connectivity abnormalities in autism show opposite trends, depending on direction and spatial scale. Brain. 2015:138:1394-409.

15. Foeller E, Feldman DE. Synaptic basis for developmental plasticity in somatosensory cortex. Curr Opin Neurobiol. 2004;14:89-95.

16. Morrison I, Löken LS, Olausson H. The skin as a social organ. Exp Brain Res. 2009;204:305-14.

17. Stanley DA, Adolphs R. Toward a neural basis for social behavior. Neuron. 2013;80:816-26

18. Björnsdotter M, Löken L, Olausson H, Vallbo A, Wessberg J. Somatotopic organization of gentle touch processing in the posterior insular cortex. J Neurosci. 2009;29:9314-20.

19. Olausson $\mathrm{H}$, Wessberg J, Morrison I, McGlone F, Vallbo A. The neurophysiology of unmyelinated tactile afferents. Neurosci Biobehav Rev. 2008;34:185-91. 